\title{
Crescimento do pinhão-manso irrigado com águas salinas em ambiente protegido ${ }^{1}$
}

\author{
Aparecida R. Nery², Luis N. Rodrigues², Maria B. R. Silva², Pedro D. Fernandes², Lúcia H. G. Chaves², José D antas Neto² \& Hans R. G heyi²
}

\begin{abstract}
RESU MO
Considerando as potencialidades de uso do pinhão manso (Jatropha curcas L.) como fonte energética e a carência de resultados de pesquisa relativos ao seu cultivo, realizou-se este trabalho com o fim primordial de se estudar os efeitos da salinidade da água de irrigação sobre o crescimento das plantas, em ambiente protegido. A pesquisa foi desenvolvida entre abril e outubro de 2007, no Centro de Tecnologia e Recursos Naturais (CTRN) da UFCG-PB. As plantas foram cultivadas em lisímetros de drenagem (200 L), contendo $230 \mathrm{~kg}$ de material de solo devidamente adubado, não-salino, não-sódico, classificado como Argissolo A cinzentado eutrófico. 0 s tratamentos consistiram de cinco níveis de condutividade elétrica da água de irrigação - CEa $\left(0,6 ; 1,2 ; 1,8 ; 2,4\right.$ e 3,0 dS m-1, a $\left.25^{\circ} \mathrm{C}\right)$, no delineamento experimental em blocos casualizados, com quatro repetições, sendo cada parcela constituída pela média de duas plantas cultivadas em lisímetros separados. Avaliaram-se altura de planta, diâmetro caulinar, número de folhas e área foliar aos 37, 58, 79, 100, 121, 142 e 163 dias após a semeadura; ao final do período de estudos, o pinhão-manso irrigado com água de CEa de 3,0 dS m-1 teve a altura de planta, o diâmetro caulinar, o número de folhas e a área foliar reduzidos em 9,07, 17,63, 23,41 e $42,58 \%$, respectivamente.
\end{abstract}

Palavras-chave: Jatropha curcas L., irrigação, condutividade elétrica

\section{Growth of Jatropha irrigated with saline water in greenhouse}

\begin{abstract}
The objective of this work was to evaluate the effects of irrigation water salinity on the growth of Jatropha curcas $L$. in greenhouse. The research was carried out during April and 0 ctober of 2007, in a greenhouse of the Department of Agricultural Engineering of the Natural Resources and Technology Center (CTRN) of Federal University of Campina Grande, Paraíba, Brazil. The plants were grown in drainage lysimeters $(200 \mathrm{~L})$ with $230 \mathrm{~kg}$ of non-saline, non-sodic soil adequately fertilized, classified as Gray Argisol eutrophic. The treatments consisted of five levels of electrical conductivity of the

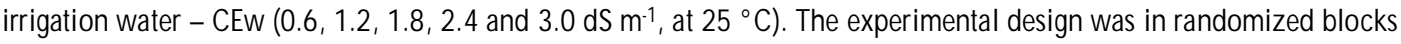
with 4 replications, each replication represented by the average of 2 plants cultivated in separate lysimeters. Plant height, stem diameter, number of leaves and leaf area were evaluated at 37, 58, 79, 100,121, 142 and 163 days after sowing

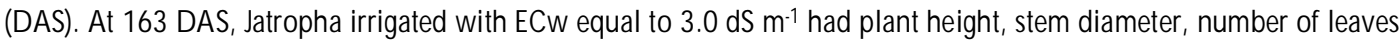
and leaf area reduced by $9.07,17.63,23.41$ and $42.58 \%$, respectively.
\end{abstract}

Key words: Jatropha curcas L., irrigation, electrical conductivity

1 Parte da Dissertação de Mestrado do primeiro autor, apresentada ao Programa de Pós-Graduação em Engenharia Agrícola/U FCG

2 UAEA/UFCG. Av. Aprígio Veloso 882, CEP 58109-970. Campina Grande, PB. Fone: (83) 3310-1285. E-mail(s): cydanery@gmail.com; luis.lunero@gmail.com; betaniars@hotmail.com; pdantas@pesquisador.cnpq.br; Ihgarofalo@hotmail.com; zedantas@deag.ufcg.edu.br; hans@deag.ufcg.edu.br 


\section{INTRODUÇÃO}

O pinhão-manso (Jatropha curcas L.) é uma planta pertencente à família Euphorbiaceae e de origem bastante duvidosa. Existem pesquisadores que o consideram nativo do Brasil mas, conforme o Anuário Brasileiro de Agroenergia - ABA (2007), seu mais provável local de origem é a América Central; outros autores, como Tominaga et al. (2007), apontam o México como seu país de origem; os índios que migraram da América do Norte para a América do Sul, há mais de dez mil anos, seriam os responsáveis por sua distribuição do México até a Argentina, incluindo o Brasil; já os autores Cáceres et al. (2007) admitem a origem na América tropical de onde foi levado, por navegadores portugueses para as demais partes tropicais do mundo.

Diante da preocupação atual com o efeito estufa, o aquecimento global e a escassez das reservas mundiais de combustível fóssil, o pinhão-manso tem despertado interesse dos produtores, do governo e das instituições de pesquisa. Desta forma, com a possibilidade do uso do óleo de pinhão-manso para a produção de biodiesel, abrem-se amplas perspectivas para o aumento das áreas de plantio com esta cultura no semiárido nordestino (Arruda et al., 2004).

Considerando-se a pressão cada vez maior sobre as fontes hídricas de boa qualidade, devem ser incentivados os estudos de uso da água salina na irrigação, identificandose o grau de tolerância das plantas à salinidade, desde que se garanta um manejo adequado de solo, água e plantas (Rhoades et al., 2000).

Nas regiões áridas e semiáridas, a salinização decorre da natureza física e química dos solos, do regime pluvial e da alta evaporação; naturalmente, o uso de irrigação acarreta a incorporação de sais ao perfil do solo, haja vista que a água contém íons solúveis e seu uso constante na ausência de lixiviação faz com que o sal se deposite na zona do sistema radicular, devido à evaporação. A drenagem restrita contribui, também, para a salinização dos solos irrigáveis, podendo influir na altura do lençol freático. A salinização do solo progride quando a quantidade de sais que nele é acumulada, pela água de irrigação, é maior que a quantidade removida pela água de drenagem (Pizarro, 1985; Ayers \& Westcot, 1999).

Sem dúvida alguma, a principal causa do aumento da salinização dos solos agrícolas têm sido as irrigações mal conduzidas e o manejo inadequado da adubação. As opções que se destacam para se evitar a salinização dos solos irrigados ou cultivar solos já salinizados, são: realizar drenagem adequada, lixiviar o excesso de sais, usar culturas mais tolerantes e utilizar métodos de irrigação adequados às condições de salinidade do solo e da água de irrigação; já com relação aos problemas causados pela salinização, podem ser citados: diminuição do potencial osmótico da solução do solo, diminuindo a retenção de água no solo; dispersão das partículas do solo, diminuindo a capacidade de infiltração e causando problemas de toxicidade às plantas. Esses problemas resultarão no decréscimo da produção agrícola de qualquer solo (Bernardo et al., 2006).

A literatura disponível sobre a cultura do pinhão-manso ainda é bastante escassa, pois passou a ser objeto de maior interesse nos últimos anos, com a crise do petróleo e a preocupação com os impactos ambientais causados pelo uso de combustíveis fósseis e, ainda, pela possibilidade de serem usados óleos vegetais como combustíveis.

Pouco se conhece sobre a bioquímica e a fisiologia desta planta; não existem cultivares definidas e alguns aspectos agronômicos ainda carecem de investigação como, por exemplo, a densidade ideal de plantas e a configuração de plantio (Beltrão, 2006); entretanto, com a possibilidade de uso do óleo de pinhão-manso para a produção do biodiesel, novas e amplas perspectivas se abrem para o aumento das áreas de plantio com esta cultura no semiárido nordestino.

Embora seja uma espécie que sobrevive em condições de seca, adaptada à semiaridez, exigente em calor e luminosidade, a garantia de produção deverá ser maior com irrigação não havendo, até agora, na literatura disponível, qualquer indicação da exigência hídrica das plantas nem do efeito de águas de qualidade marginal, sobre a produção. Objetivou-se, com esta pesquisa, avaliar o crescimento do pinhãomanso irrigado com águas de diferentes níveis de salinidade em ambiente protegido.

\section{MATERIAL E MÉTODOS}

O experimento foi desenvolvido entre os meses de abril e outubro de 2007, em instalações pertencentes ao Centro de Tecnologia e Recursos Naturais (CTRN) da UFCG, em Campina Grande, $\mathrm{PB}$, com as seguintes coordenadas geográficas: latitude $07^{\circ} 13^{\prime} \mathrm{S}$, longitude $35^{\circ} 53^{\prime} \mathrm{W}$ e altitude média $550 \mathrm{~m}$. Foi utilizado o acesso de pinhão-manso (Jatropha curcas L.) FT 02, cujas sementes foram cedidas pela Fazenda Tamanduá, localizada no município de Patos, PB. A semeadura foi realizada no dia 07/04/2007, em tubetes de $200 \mathrm{~cm}^{3}$ contendo substrato orgânico; previamente à semeadura, fez-se a seleção das sementes, eliminando-se as defeituosas e com indícios de fungos, ataques de insetos e danos mecânicos.

O material de solo (Argissolo Acinzentado Eutrófico) utilizado no experimento procedeu do Distrito de São José da Mata (Campina Grande), coletado na profundidade de 0-30 cm (horizonte A).

Utilizaram-se de 40 vasos cilíndricos com capacidade de $200 \mathrm{~L}(\mathrm{D}=0,58 \mathrm{~m}$ e $\mathrm{H}=0,75 \mathrm{~m}$ ), funcionando como lisímetros de drenagem, contendo, cada um, $230 \mathrm{~kg}$ de material de solo; o sistema de drenagem, instalado na base dos lisímetros, foi composto de tela de nylon, 5,0 L de brita, 5,0 L de areia e duas mangueiras, conectadas externamente a dois recipientes coletores de 2 L. Realizou-se adubação de plantio com base em recomendações contidas em Novais et al. (1991) para experimentos conduzidos em ambiente protegido, correspondendo, no presente experimento, a: $94,00 \mathrm{mg} \mathrm{kg}^{-1}$ de uréia (45\% $\mathrm{N}) ; 577,00 \mathrm{mg} \mathrm{kg}^{-1}$ de $\mathrm{MAP}\left(52,0 \% \mathrm{P}_{2} \mathrm{O}_{5}\right.$ e $\left.10,0 \% \mathrm{~N}\right)$ e $312,50 \mathrm{mg} \mathrm{kg}^{-1} \mathrm{de} \mathrm{K}_{2} \mathrm{SO}_{4}\left(48,0 \% \mathrm{~K}_{2} \mathrm{O}\right)$.

Para a calagem adotou-se o método que resultou em maior necessidade de calcário (elevação das bases trocáveis $\mathrm{NC}=[2 \times \mathrm{Al}+2,0-(\mathrm{Ca}+\mathrm{Mg})] \times \mathrm{F})$, conforme resultados 
da análise química apresentados na Tabela 1; para tal, utilizou-se calcário dolomítico na proporção de $750 \mathrm{mg} \mathrm{kg}^{-1}$; os adubos e o calcário foram incorporados ao solo, devidamente destorroados, por ocasião do enchimento dos lisímetros. O material de solo contido em cada lisímetro foi mantido em capacidade de campo, com o fornecimento diário de dois litros de água de modo a possibilitar maior velocidade de reação do calcário; no dia 26/04/2007, em cada um dos 40 lisímetros foi transplantada uma planta de pinhão manso, previamente selecionada, com a idade de 19 dias após a semeadura (DAS), emitindo a segunda folha definitiva.

Tabela 1. Características físico-hídricas e químicas do solo utilizado na pesquisa. Campina Grande, PB, 2007

\begin{tabular}{|c|c|c|}
\hline Atributo físico-hídrico & Unidade & Valor \\
\hline Areia & $\mathrm{g} \mathrm{kg}^{-1}$ & 733 \\
\hline Silte & $\mathrm{g} \mathrm{kg}^{-1}$ & 84 \\
\hline Argila & $\mathrm{g} \mathrm{kg}^{-1}$ & 183 \\
\hline Classificação textural & - & Franco-arenoso \\
\hline Densidade do solo (ds) & $\mathrm{kg} \mathrm{dm}^{-3}$ & 1,60 \\
\hline Densidade das partículas (dp) & $\mathrm{kg} \mathrm{dm}^{-3}$ & 2,75 \\
\hline Porosidade $(\varepsilon)$ & $\%$ & 41,82 \\
\hline Capacidade de campo (10,13 kPa) & $\mathrm{g} \mathrm{kg}^{-1}$ & 82,00 \\
\hline Ponto de murchamento (1519,87 kPa) & $\mathrm{g} \mathrm{kg}^{-1}$ & 20,50 \\
\hline Água disponível & $\mathrm{g} \mathrm{kg}^{-1}$ & 61,50 \\
\hline Atributo químico & Unidade & $\begin{array}{c}\text { Valor }^{1} \\
\text { Antes - Após }\end{array}$ \\
\hline Cálcio extraível $\left(\mathrm{Ca}^{+2}\right)$ & $\mathrm{Cmol}_{\mathrm{c}} \mathrm{dm}^{-3}$ & $0,67-1,25$ \\
\hline Magnésio extraível $\left(\mathrm{Mg}^{+2}\right)$ & $\mathrm{Cmol}_{\mathrm{c}} \mathrm{dm}^{-3}$ & $1,19-1,55$ \\
\hline Sódio extraível $\left(\mathrm{Na}^{+}\right)$ & $\mathrm{Cmol}_{\mathrm{c}} \mathrm{dm}^{-3}$ & $0,03-0,03$ \\
\hline Potássio extraível (K+) & $\mathrm{Cmol}_{\mathrm{c}} \mathrm{dm}^{-3}$ & $0,07-0,30$ \\
\hline Soma das bases $(\mathrm{S})$ & $\mathrm{Cmol}_{\mathrm{c}} \mathrm{dm}^{-3}$ & $1,96-3,13$ \\
\hline Hidrogênio extraível $\left(\mathrm{H}^{+}\right)$ & $\mathrm{Cmol}_{\mathrm{c}} \mathrm{dm}^{-3}$ & $0,55-0,20$ \\
\hline Aluminio extraível $\left(\mathrm{Al}^{+3}\right)$ & $\mathrm{Cmol}_{\mathrm{c}} \mathrm{dm}^{-3}$ & $0,80-0,05$ \\
\hline Capacidade de troca catiônica (CTC) & $\mathrm{Cmol}_{\mathrm{c}} \mathrm{dm}^{-3}$ & $3,31-3,38$ \\
\hline Saturação de bases (V) & $\%$ & $59,21-92,60$ \\
\hline Percentagem de sódio trocável (PST) & $\%$ & $0,91-0,89$ \\
\hline Carbono orgânico (C-Org.) & $\mathrm{g} \mathrm{kg}^{-1}$ & $1,10-1,10$ \\
\hline Matéria orgânica (M.0.) & $\mathrm{g} \mathrm{kg}^{-1}$ & $1,90-1,90$ \\
\hline Nitrogênio (N-Org.) & $\mathrm{g} \mathrm{kg}^{-1}$ & $0,09-0,09$ \\
\hline Fósforo assimilável (P) & $\mathrm{mg} \mathrm{kg}^{-1}$ & $0,10-81,60$ \\
\hline pH em água $(1: 2,5)$ & - & $5,20-6,18$ \\
\hline CE da suspensão solo-água $(1: 2,5)$ (CEsa) & $\mathrm{dS} \mathrm{m}^{-1}$ & $0,19-0,29$ \\
\hline
\end{tabular}

Análises realizadas no Laboratório de Irrigação e Salinidade do Centro de Tecnologia e Recursos Naturais (CTRN/UFCG)

${ }^{1}$ Análises realizadas antes e 24 dias após a calagem

Cinco níveis de condutividade elétrica da água de irrigação - CEa $\left(\mathrm{N}_{1}=0,60 ; \mathrm{N}_{2}=1,20 ; \mathrm{N}_{3}=1,80 ; \mathrm{N}_{4}=2,40 \mathrm{e}\right.$ $\mathrm{N}_{5}=3,00 \mathrm{dS} \mathrm{m}^{-1}$, a $25^{\circ} \mathrm{C}$ ) foram testados e delineados em blocos casualizados, com quatro repetições, sendo a parcela constituída de 2 plantas ( 1 planta/lisímetro), perfazendo o total de 40 lisímetros; as parcelas experimentais ficaram espaçadas $1,70 \mathrm{~m}$ x 1,40 m dentro do bloco e 1,60 m entre blocos.

Para o preparo das soluções salinas foram utilizados os sais $\mathrm{NaCl}, \mathrm{CaCl}_{2} \cdot 2 \mathrm{H}_{2} \mathrm{O}$ e $\mathrm{MgCl}_{2} \cdot 6 \mathrm{H}_{2} \mathrm{O}$, na proporção equivalente 7:2:1, entre os cátions $\mathrm{Na}^{+}: \mathrm{Ca}^{++}: \mathrm{Mg}^{++}$, relação esta baseada em resultados de estudos realizados por Medeiros (1992), em águas de pequenos mananciais do Nordeste bra- sileiro; na composição das águas salinas utilizou-se da água de abastecimento público.

O início da aplicação dos tratamentos ocorreu aos 37 DAS (18 dias após o transplantio), com turno de rega de 2 dias; as plantas foram irrigadas sob diferentes frações de lixiviação, $4,8,12,16$ e $20 \%$ para os tratamentos $\mathrm{N}_{1}, \mathrm{~N}_{2}, \mathrm{~N}_{3}, \mathrm{~N}_{4} \mathrm{e}$ $\mathrm{N}_{5}$, respectivamente, e as irrigações foram manejadas e controladas mediante o uso de planilha eletrônica; na primeira irrigação (após estarem todos os lisímetros em capacidade de campo) aplicaram-se 2,0 L de água em cada parcela de todos os tratamentos, para possibilitar o controle das frações de lixiviação e o balanço hídrico, a definirem o volume aplicado nas irrigações seguintes.

Periodicamente, realizaram-se adubações de cobertura com N-P-K e adubações foliares com micronutrientes, em especial para suprir a deficiência de zinco e cobre, e, também, pulverizações para o controle de várias pragas, dentre elas pulgões, cigarrinha, mosca branca e, sobretudo, para o controle do ácaro branco, Polyphagotarsonemus latus Banks. Adotaram-se, para os tratamentos fitossanitários, todas as medidas culturais indicadas para o controle, além da rotação dos agroquímicos com extratos vegetais - óleo de pinhão-manso e óleo de 'neem' (Azadirachta indica) -, objetivando-se evitar o surgimento de resistência.

Realizaram-se quatro adubações de cobertura, em que nas duas primeiras (114 e $128 \mathrm{DAS}$ ) se aplicaram 3,0 g de $\left(\mathrm{NH}_{4}\right)_{2} \mathrm{SO}_{4}+4,00 \mathrm{~g} \mathrm{KCl}$ por planta e, nas últimas $(142 \mathrm{e}$ $161 \mathrm{DAS}), 3,0 \mathrm{~g}$ de $\left(\mathrm{NH}_{4}\right)_{2} \mathrm{SO}_{4}$. Seis pulverizações foram realizadas com uma solução de $\mathrm{Zn}+\mathrm{Cu}(0,50 \%)$ aos 38,48 , 53, 65, 72 e 81 DAS e, aos 149 DAS, fez-se adubação foliar com o produto comercial Albatrós (N-P-K-Mg: 7-17-35-3, + micronutrientes).

As variáveis altura de planta, diâmetro caulinar, número de folhas e área foliar foram avaliadas aos 37, 58, 79, 100, 121,142 e 163 DAS, e os dados submetidos às análises de variância e de regressão polinomial, utilizando-se do software estatístico SISVAR-ESAL (Lavras, MG). De acordo com Santos et al. (1998), os quatro graus de liberdade dos tratamentos ' $\mathrm{N}$ ' (níveis salinos) foram decompostos em componentes de regressão polinomial (linear, quadrática, cúbica e de quarto grau), optando-se pelo modelo de mais alto grau significativo, para construção das figuras.

\section{RESULTADOS E DISCUSSÃO}

\section{Altura de planta (AP)}

Constatou-se efeito significativo $(\mathrm{p}<0,05)$ dos níveis salinos sobre a altura de plantas, apenas aos 79 e 100 dias (Tabela 2A); entretanto, com a decomposição dos graus de liberdade do fator nível salino, a altura foi afetada linearmente pela condutividade elétrica da água de irrigação ao longo do experimento. A aplicação dos tratamentos teve início aos 37 DAS, quando se fez a primeira avaliação das plantas, razão pela qual não houve efeito da salinidade nesta data.

Com base nas equações contidas na Figura 1A e 1B, os decréscimos verificados na altura da planta entre $\mathrm{N}_{1}$ $\left(0,60 \mathrm{dS} \mathrm{m}^{-1}\right)$ e $\mathrm{N}_{5}\left(3,00 \mathrm{dS} \mathrm{m}^{-1}\right)$ foram $8,57,14,01,10,79$, 
Tabela 2. Resumo das análises de variância para altura de planta (A), diâmetro caulinar (B), número de folhas (C) e área foliar (D) do pinhão-manso aos 35, 58, 79, 100, 121, 142 e 163 dias após a semeadura - DAS

\begin{tabular}{|c|c|c|c|c|c|c|c|c|}
\hline Datas & GL & 37 DAS & 58 DAS & 79 DAS & 100 DAS & 121 DAS & 142 DAS & 163 DAS \\
\hline F. Variação & \multicolumn{8}{|c|}{ A - Quadrados médios da altura de plantas (AP) } \\
\hline N. salino $(\mathrm{N})$ & 4 & $1,105^{\text {NS }}$ & $14,106^{\mathrm{NS}}$ & $94,625^{*}$ & $93,700 *$ & $70,731^{\mathrm{NS}}$ & $141,500^{\mathrm{NS}}$ & $107,419^{\text {NS }}$ \\
\hline R. linear & 1 & $3,452^{\text {NS }}$ & $45,156^{*}$ & $336,400 * *$ & $366,025^{* *}$ & $280,556^{*}$ & $547,600 * *$ & $412,806^{*}$ \\
\hline R. quadrática & 1 & $0,590^{\text {NS }}$ & $1,612^{\mathrm{NS}}$ & $4,571^{\mathrm{NS}}$ & $0,446^{\mathrm{NS}}$ & $0,254^{\text {NS }}$ & $4,571^{\text {NS }}$ & $9,040^{\mathrm{NS}}$ \\
\hline R. cúbica & 1 & $0,189^{\text {NS }}$ & $0,000^{\mathrm{NS}}$ & $0,006^{\mathrm{NS}}$ & $8,100^{\text {NS }}$ & $0,756^{\mathrm{NS}}$ & $13,806^{\mathrm{NS}}$ & $2,256^{\mathrm{NS}}$ \\
\hline R. $4^{\circ}$ grau & 1 & $0,188^{\text {NS }}$ & $9,657^{\mathrm{NS}}$ & $37,522^{\mathrm{NS}}$ & $0,229^{\text {NS }}$ & $1,358^{\mathrm{NS}}$ & $0,022^{\mathrm{NS}}$ & $5,572^{\mathrm{NS}}$ \\
\hline Blocos & 3 & $6,145^{\mathrm{NS}}$ & $46,046^{*}$ & $85,500 *$ & $17,400^{\mathrm{NS}}$ & $80,833^{\text {NS }}$ & $154,983^{\mathrm{NS}}$ & $148,513^{\mathrm{NS}}$ \\
\hline Resíduo & 12 & 1,934 & 8,639 & 18,916 & 27,900 & 57,406 & 49,400 & 52,502 \\
\hline $\mathrm{CV}(\%)$ & & 5,98 & 6,19 & 5,65 & 4,98 & 6,34 & 5,61 & 5,36 \\
\hline F. Variação & \multicolumn{8}{|c|}{ B - Quadrados médios do diâmetro caulinar (DC) } \\
\hline N. salino $(N)$ & 4 & $0,461^{\mathrm{NS}}$ & $3,031^{\mathrm{NS}}$ & $10,370 * *$ & $16,554^{* *}$ & $32,505^{* *}$ & $44,837 * *$ & $56,107 * *$ \\
\hline R. linear & 1 & $0,006^{\mathrm{NS}}$ & $9,361^{*}$ & $39,105^{* *}$ & $62,500 * *$ & $127,600 * *$ & $172,018 * *$ & $211,830 * *$ \\
\hline R. quadrática & 1 & $0,601^{\mathrm{NS}}$ & $0,055^{\mathrm{NS}}$ & $1,072^{\mathrm{NS}}$ & $0,086^{\mathrm{NS}}$ & $1,646^{\mathrm{NS}}$ & $0,814^{\mathrm{NS}}$ & $2,903^{\mathrm{NS}}$ \\
\hline R. cúbica & 1 & $0,900^{\mathrm{NS}}$ & $0,441^{\mathrm{NS}}$ & $0,138^{\mathrm{NS}}$ & $3,025^{\text {NS }}$ & 0,656 NS & $6,320^{\mathrm{NS}}$ & $9,604^{\mathrm{NS}}$ \\
\hline R. $4^{\circ}$ grau & 1 & $0,336^{\mathrm{NS}}$ & $2,268^{\mathrm{NS}}$ & $1,164^{\text {NS }}$ & $0,604^{\mathrm{NS}}$ & $0,116^{\mathrm{NS}}$ & $0,196^{\mathrm{NS}}$ & $0,089^{N S}$ \\
\hline Blocos & 3 & $1,608 *$ & $10,554 * *$ & $7,190 *$ & $8,006^{* *}$ & $4,433^{*}$ & $6,799 * *$ & $7,625^{*}$ \\
\hline Resíduo & 12 & 0,365 & 1,402 & 1,589 & 1,250 & 0,985 & 1,761 & 2,055 \\
\hline $\mathrm{CV}(\%)$ & & 5,27 & 5,81 & 4,58 & 3,24 & 2,42 & 2,93 & 3,01 \\
\hline F. Variação & \multicolumn{8}{|c|}{ C - Quadrados médios do número de folhas (NF) } \\
\hline N. salino $(\mathrm{N})$ & 4 & $0,519^{\text {NS }}$ & $11,481^{\mathrm{NS}}$ & $993,98 *$ & $2421,500 * *$ & $3517,575^{* *}$ & $2726,425 * *$ & $7467,950^{* *}$ \\
\hline R. linear & 1 & $0,306^{\mathrm{NS}}$ & $39,006^{\mathrm{NS}}$ & $3868,906 * *$ & $8940,100 * *$ & $12320,10^{* *}$ & $10064,756 * *$ & $27808,90 * *$ \\
\hline R. quadrática & 1 & $0,540^{\mathrm{NS}}$ & $0,218^{\mathrm{NS}}$ & $45,540^{\text {NS }}$ & $185,786^{\text {NS }}$ & $1340,643^{\mathrm{NS}}$ & $537,540^{\mathrm{NS}}$ & $1016,071^{\text {NS }}$ \\
\hline R. cúbica & 1 & $0,006^{\mathrm{NS}}$ & $0,400^{\text {NS }}$ & $15,625^{\mathrm{NS}}$ & $16,900^{\mathrm{NS}}$ & $48,400^{\text {NS }}$ & $78,4000^{N S}$ & $967,006^{\text {NS }}$ \\
\hline R. $4^{0}$ grau & 1 & $1,222^{\mathrm{NS}}$ & $6,300^{\mathrm{NS}}$ & $45,604^{\mathrm{NS}}$ & $543,214^{\text {NS }}$ & $361,157^{\text {NS }}$ & $225,0036^{\text {NS }}$ & $79,822^{\text {NS }}$ \\
\hline Blocos & 3 & $4,512^{\mathrm{NS}}$ & $74,983^{*}$ & $1198,750 *$ & $1994,133^{*}$ & $5235,146^{* *}$ & $3705,033 * *$ & $189,246^{\mathrm{NS}}$ \\
\hline Resíduo & 12 & 1,6687 & 20,0562 & 276,718 & 452,633 & 580,083 & 509,575 & 400,725 \\
\hline CV $(\%)$ & & 15,80 & 12,82 & 18,35 & 13,91 & 11,61 & 10,25 & 7,95 \\
\hline F. Variação & \multicolumn{8}{|c|}{ D - Quadrados médios da área foliar (AF) } \\
\hline N. salino $(N)$ & 4 & $4,6 \mathrm{E}-05^{\mathrm{NS}}$ & $0,0037^{\mathrm{NS}}$ & $0,0617^{*}$ & $0,2384 * *$ & $0,5467^{* *}$ & $0,6836 * *$ & $0,5674 * *$ \\
\hline R. linear & 1 & $1,0 \mathrm{E}-05^{\mathrm{NS}}$ & $0,0099^{N S}$ & $0,2005^{* *}$ & $0,9208 * *$ & $2,0563^{* *}$ & $2,7220 * *$ & $2,1940 * *$ \\
\hline R. quadrática & 1 & $4,9 \mathrm{E}-05^{\mathrm{NS}}$ & $0,0036^{\mathrm{NS}}$ & $0,0384^{\mathrm{NS}}$ & $0,0045^{\mathrm{NS}}$ & $0,0310^{\mathrm{NS}}$ & $0,0001^{\mathrm{NS}}$ & $0,0019^{\text {NS }}$ \\
\hline R. cúbica & 1 & $8,0 \mathrm{E}-06^{\mathrm{NS}}$ & $0,0005^{\mathrm{NS}}$ & $0,0043^{\mathrm{NS}}$ & $0,0137^{\mathrm{NS}}$ & $0,0889^{\mathrm{NS}}$ & $0,0067^{\mathrm{NS}}$ & $0,0143^{\text {NS }}$ \\
\hline R. $4^{\circ}$ grau & 1 & $1,2 \mathrm{E}-04^{\mathrm{NS}}$ & $0,0009^{\text {NS }}$ & $0,0038^{\mathrm{NS}}$ & $0,0148^{\mathrm{NS}}$ & $0,0106^{\mathrm{NS}}$ & $0,0055^{\mathrm{NS}}$ & $0,0593^{\text {NS }}$ \\
\hline Blocos & 3 & $2,3 \mathrm{E}-04^{\mathrm{NS}}$ & $0,0132 *$ & $0,0724 *$ & $0,1466^{*}$ & $0,3266 * *$ & $0,2501^{*}$ & $0,0094^{\mathrm{NS}}$ \\
\hline Resíduo & 12 & 9,3E-05 & 0,0023 & 0,0164 & 0,0357 & 0,0399 & 0,0488 & 0,0181 \\
\hline $\mathrm{CV}(\%)$ & & 15,20 & 16,63 & 18,31 & 13,74 & 11,99 & 12,15 & 7,78 \\
\hline
\end{tabular}

$\left(^{* *}\right)$ Efeito significativo a $1 \%$ e $\left(^{*}\right)$ a $5 \%$ de probabilidade; (NS) não significativo a nível de $5 \%$ de probabilidade pelo teste $\mathrm{F}$

$8,14,11,16$ e $9,07 \%$ aos $58,79,100,121,142$ e 163 DAS, respectivamente. Considerando-se, ao final da pesquisa, ter sido o decréscimo inferior a $10 \%$, deduz-se que a altura do pinhão-manso foi medianamente afetada pela salinidade.

A evolução da altura de plantas em função dos dias após a semeadura (variação temporal) e por nível de salinidade da água de irrigação, está apresentada na Figura 1C, na qual se nota crescimento mais pronunciado até os 100 dias após a semeadura, quando as plantas iniciaram o florescimento.

Vale et al. (2006) verificaram, ao submeterem o pinhãomanso a níveis crescentes de salinidade da água de irrigação, em casa-de-vegetação, na fase inicial de crescimento (30 dias após a emergência), que a altura do pinhão-manso foi afetada pela condutividade elétrica da água; entre as plantas irrigadas com águas de condutividade elétrica de 0,06 e 4,20 dS m${ }^{-1}$, constataram redução da altura da planta de 19,7 para $13,3 \mathrm{~cm}$, correspondendo a cerca de $7,85 \%$ por aumento unitário de CEa.
Com poucos trabalhos sobre salinidade em pinhão-manso, ressaltam-se resultados obtidos com outras oleaginosas; em ambiente protegido, Cavalcanti (2003) e Cavalcanti et al. (2005a) observaram, em estudo sobre o comportamento da mamona irrigada com águas de condutividade elétrica variando entre 0,7 e $4,7 \mathrm{dS} \mathrm{m}^{-1}$, redução de $23,40 \%$ (5,85\% para cada $\mathrm{dS} \mathrm{m}^{-1}$ ) na AP para a cultivar BRS Nordestina; Silva (2004), estudando a BRS Paraguaçu, com CEa variando de 0,7 a $8,7 \mathrm{dS} \mathrm{m}^{-1}$, observou um decréscimo de $78,10 \%(9,76 \%$ para cada dS $\mathrm{m}^{-1}$ ). Correia et al. (2005) constataram, em trabalho com estresse salino em amendoim, com CEa variando de 0,4 a $6,0 \mathrm{dS} \mathrm{m}^{-1}$, que a salinidade afetou as plantas em termos de altura, com redução de $3,29 \%$ por incremento unitário da CEa. Notou-se, na presente pesquisa, decréscimo unitário de 3,78\%, denotando que o crescimento em altura do pinhão-manso foi menos afetado que o da mamoneira e do amendoim.

Na literatura são encontradas, também, referências à 
A.
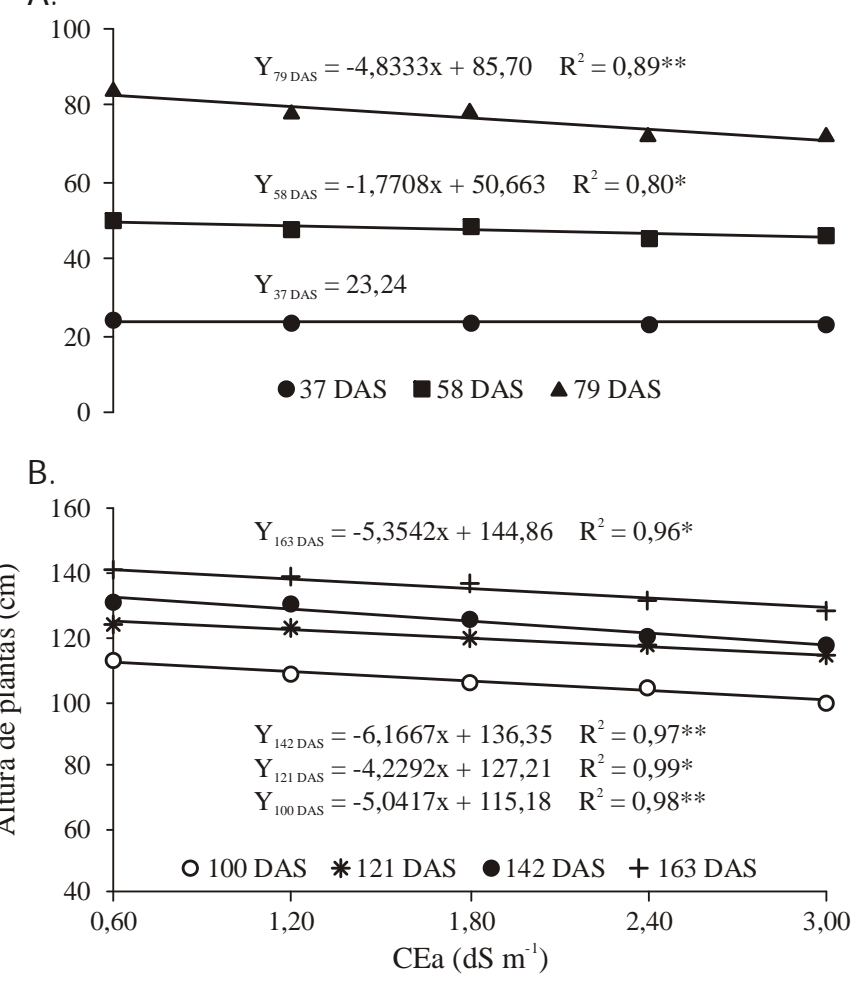

C.

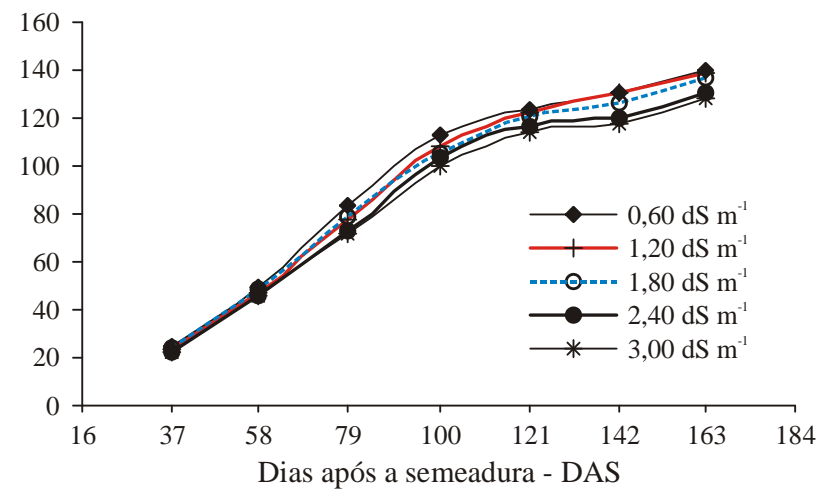

Figura 1. Altura de plantas de pinhão-manso aos 37, 58 e 79 dias após a semeadura - DAS (A) e aos 100, 121, 142 e 163 DAS (B), em função da condutividade elétrica da água de irrigação (CEa) e sua evolução temporal (C), em função do período de estudos

redução na altura de plantas devido aos efeitos negativos ocasionados pelo aumento da salinidade em algodão (Arruda, 1999; Queiroz \& Bull, 2001; Jácome et al., 2005).

\section{Diâmetro caulinar (DC)}

Foram igualmente significativos os efeitos dos níveis salinos sobre o diâmetro do caule do pinhão-manso, a partir de 58 DAS (Tabela 2B). À semelhança da altura, o diâmetro também foi afetado linearmente pela condutividade elétrica da água de irrigação (Figura 2A e B), com decréscimos entre $\mathrm{N}_{1}\left(0,60 \mathrm{dS} \mathrm{m}^{-1}\right)$ e $\mathrm{N}_{5}\left(3,00 \mathrm{dS} \mathrm{m}^{-1}\right)$ de 9,06, 13,41, $13,52,15,33,16,78$ e $17,63 \%$ aos $58,79,100,121,142 \mathrm{e}$ 163 DAS, respectivamente. Deduz-se, com base nesses decréscimos, que o diâmetro foi mais sensível que a altura, notadamente nas últimas avaliações.

Apesar do efeito da salinidade, em cada época de avalia- ção, ao longo de todo o período experimental o diâmetro do caule cresceu (Figura 2C) com tendência linear; maiores valores de diâmetro foram registrados sob os menores níveis salinos. Nas avaliações finais foram, praticamente, equivalentes os valores de diâmetro das plantas irrigadas com águas de 0,60 e $1,20 \mathrm{dS} \mathrm{m}^{-1}$; comportamento semelhante também foi encontrado entre os dois níveis salinos mais elevados. Notou-se, na última avaliação (163 DAS), com base no modelo matemático (Figura 2B), decréscimo de 7,35\% por aumento unitário da CEa, sendo inferior, portanto, aos 9,46\% registrados por Silva (2004), aos 100 DAS, em estudo com a mamoneira; por outro lado, Cavalcanti et al. (2005a) observaram, aos 80 dias após a germinação, menor redução no diâmetro de caule da mamoneira, com declínio de $0,2 \mathrm{~mm}$ $(1,45 \%)$ por aumento unitário da CEa. É comum haver diferenças dos efeitos salinos entre as espécies vegetais, entre

A.

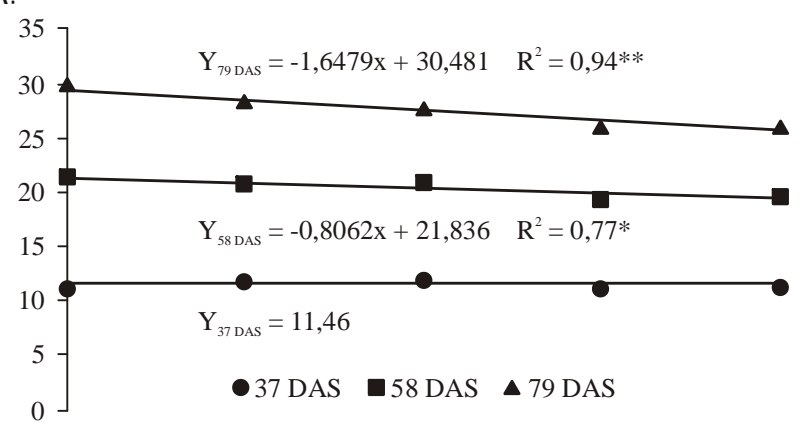

B.

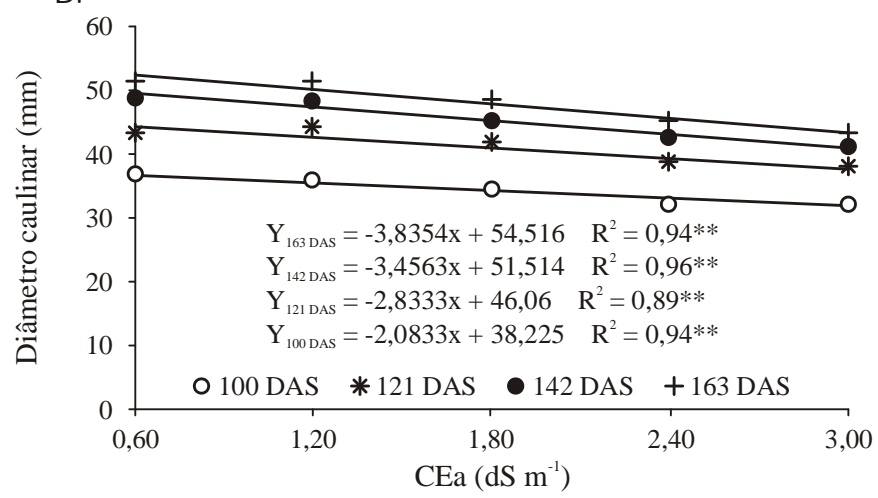

C.

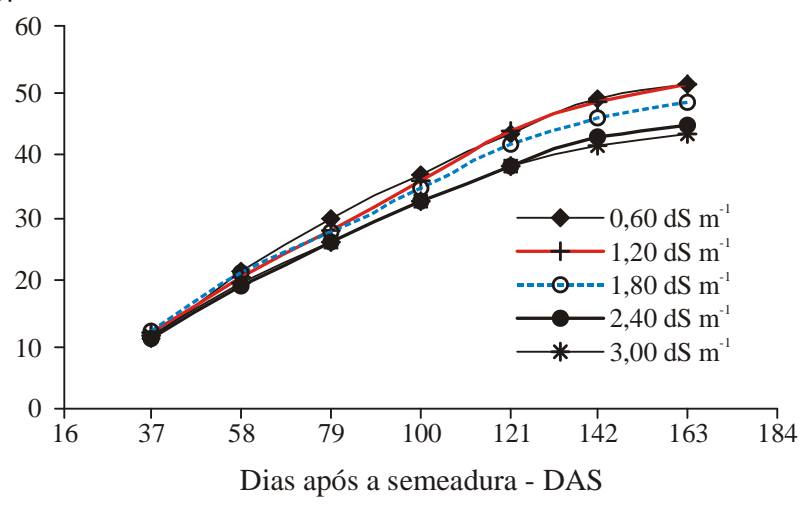

Figura 2. Diâmetro caulinar de plantas de pinhão-manso aos 37, 58 e 79 dias após a semeadura - DAS (A) e aos 100, 121, 142 e 163 DAS (B), em função da condutividade elétrica da água de irrigação (CEa) e sua evolução temporal (C), ao longo do período de estudos 
genótipos de uma mesma espécie e entre estádios de desenvolvimento de um mesmo genótipo (Taiz \& Zeiger, 2004).

Vale et al. (2006) constataram, na fase inicial de crescimento (30 dias após a emergência), que o diâmetro caulinar do pinhão-manso foi afetado, linearmente, pela condutividade elétrica da água, com redução de 7,68\% por unidade de CEa, efeito semelhante ao observado na altura $(7,85 \%)$. Em termos médios, o DC variou entre $11,46 \mathrm{~mm}$ aos 37 dias e 47,61 mm, aos 163 dias.

\section{Número de folhas (NF)}

Os resumos da análise de variância desta variável, ao longo do tempo, estão apresentados na Tabela 2C. Observa-se, a partir dos 79 DAS, que os níveis salinos afetaram significativa e linearmente o número de folhas $(\mathrm{p}<0,01)$, pelo teste $\mathrm{F}$, sem efeitos antes dessa data. Os decréscimos em 'NF', estimados a partir dos modelos matemáticos, apresentados na Figura 3A e B, entre $\mathrm{N}_{1}$ e $\mathrm{N}_{5}$, foram 34,09, 32,70, 28,93, 25,18 e $23,41 \%$ aos $79,100,121,142$ e 163 DAS, respectivamente, sendo o número de folhas, portanto, mais afetado pelo estresse salino que a altura e o diâmetro caulinar.

Na Figura 3C estão os dados de NF, ao longo do período de estudos, notando-se que as plantas irrigadas com água de CE de 1,20 e $1,80 \mathrm{dS} \mathrm{m}^{-1}$ emitiram, praticamente, o mesmo número de folhas. Nota-se, ainda, nessa figura, uma tendência de se aproximar o efeito da salinidade entre os níveis de concentração de sais, na última avaliação, aos 163 DAS, com exceção do nível mais alto de condutividade elétrica $\left(3,00 \mathrm{dS} \mathrm{m}^{-1}\right)$, uma indicação da sensibilidade do pinhão-manso a esse nível de salinidade. O número de folhas por planta variou, em média, entre 8 aos 37 dias e 258 aos 163 dias.

Vale et al. (2006), ao avaliarem o crescimento inicial do pinhão-manso (30 dias após a emergência), sob condições controladas, observaram redução de $40 \%$ no número de folhas (de 10,0 para 6,0) correspondendo a cerca de $9,66 \%$ por unidade de $\mathrm{CEa}$, sendo mais afetada que a altura $(7,85 \%)$ e que o diâmetro caulinar $(7,68 \%)$; os autores concluíram ser o pinhão-manso uma espécie sensível à salinidade da água de irrigação.

Silva (2004), aos 60 DAS, em estudos com cultivares de mamoneira, e Correia (2005), aos 105 DAS, com cultivares de amendoim, verificaram redução linear do número de folhas, com decréscimos na ordem de $8,0 \%$, por incremento unitário da salinidade da água de irrigação, um pouco inferior a $9,75 \%$, decréscimo unitário este constatado aos 163 DAS, na presente pesquisa.

Decréscimos observados no número de folhas quando as plantas são cultivadas na presença de alta salinidade, ocorrem como forma de adaptação, no sentido de minimizar as perdas de água por transpiração (Maas \& Nieman, 1978; Shannon, 1979; Fageria, 1989).

\section{Área foliar (AF)}

Observaram-se, com as análises estatísticas, efeitos significativos dos níveis salinos sobre a AF, a nível de 0,01 de probabilidade, pelo teste F, a partir de 79 DAS (Tabela 2D). Com base nas equações apresentadas na Figura 4A e B, constata-
A.
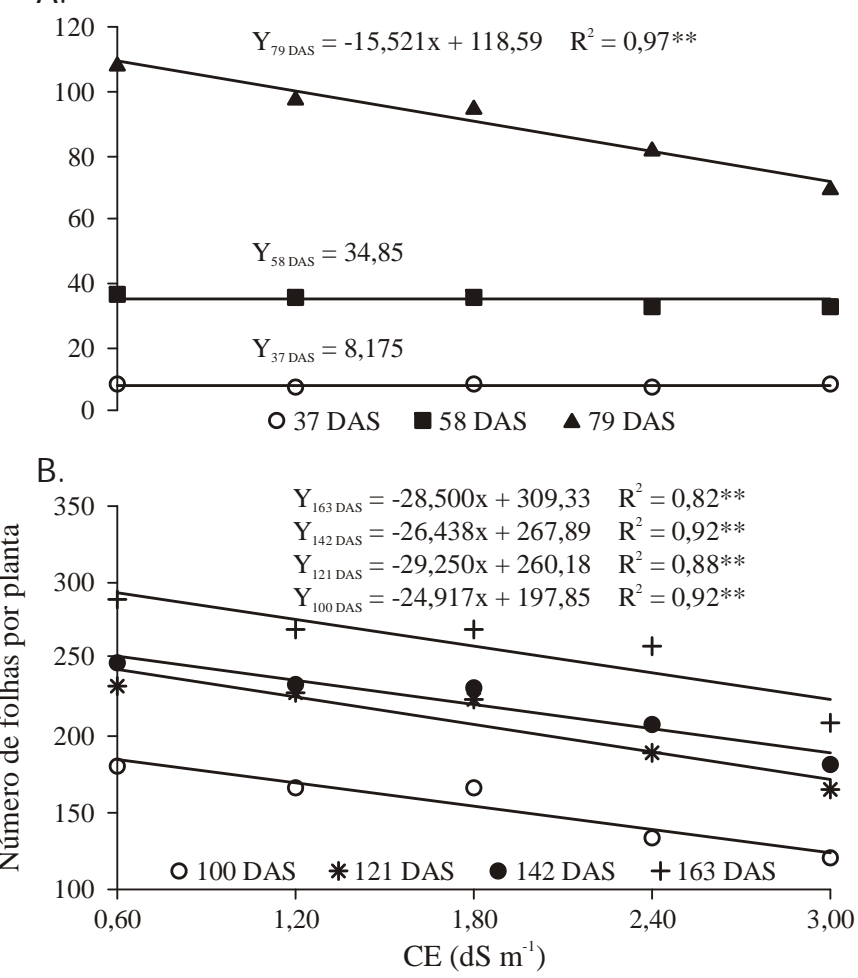

C.

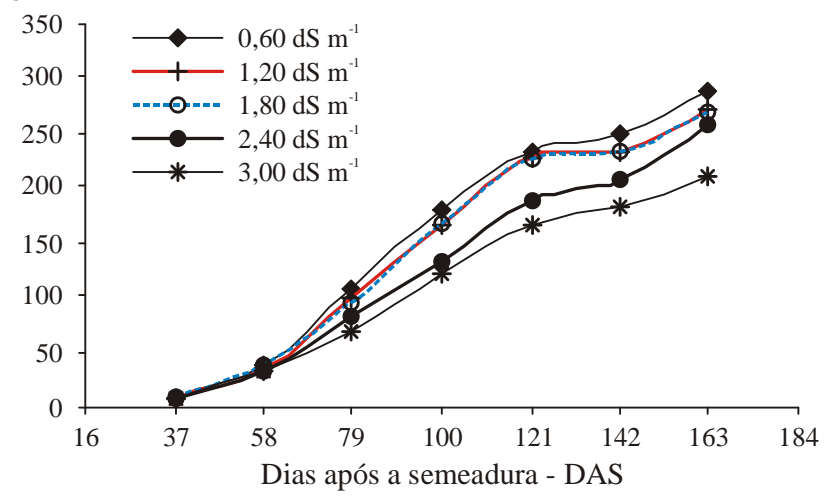

Figura 3. N úmero de folhas de plantas de pinhão-manso aos 37, 58 e 79 dias após a semeadura - DAS (A) e aos 100, 121, 142 e 163 DAS (B), em função da condutividade elétrica da água de irrigação (CEa) e sua evolução temporal (C) ao longo do período experimental

ram-se decréscimos de 33,69, 36,16, 42,79, 44,59 e 42,58\% entre $\mathrm{N}_{1}$ e $\mathrm{N}_{5}$, aos 79,100,121, 142 e 163 DAS, respectivamente; deduz-se, então, que a área foliar, aparelho assimilatório da planta, foi, dentre as variáveis de crescimento, a mais afetada, evidenciando a sensibilidade do pinhão-manso à condição de estresse salino a que foi submetida.

Cavalcanti et al. (2005b) observaram, em estudos com mamoneira sob condições salinas $\left(0,70\right.$ a $\left.4,70 \mathrm{dS} \mathrm{m}^{-1}\right)$, aos 80 dias após a germinação, que a salinidade da água de irrigação afetou significativamente a área foliar, decrescendo, linearmente, cerca de $181 \mathrm{~cm}^{2}(6,55 \%)$ por aumento unitário da CEa. Silva et al. (2005) notaram, aos 60 DAS, que a área foliar da mamoneira (irrigação com água de 0,70 a $8,70 \mathrm{dS} \mathrm{m}^{-1}$ ) foi reduzida em mais de $11,0 \%$ por incremento unitário de CE. Nesta pesquisa com pinhão-manso, observou-se efeito mais intenso; aos 79 DAS e aos 163 DAS, foram 
A.

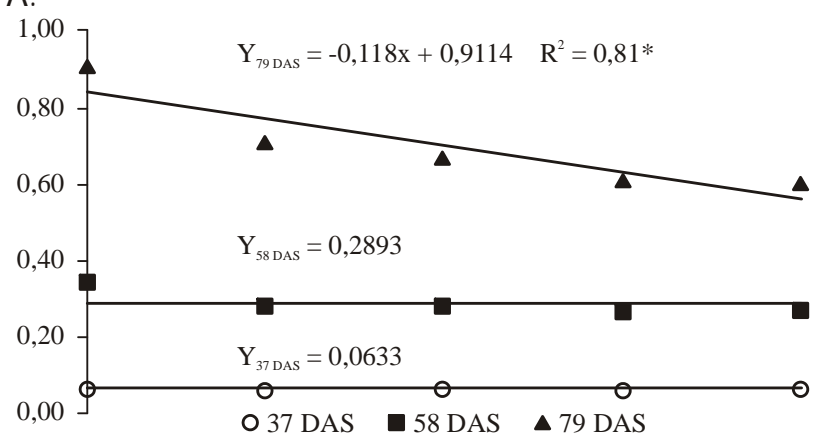

B.

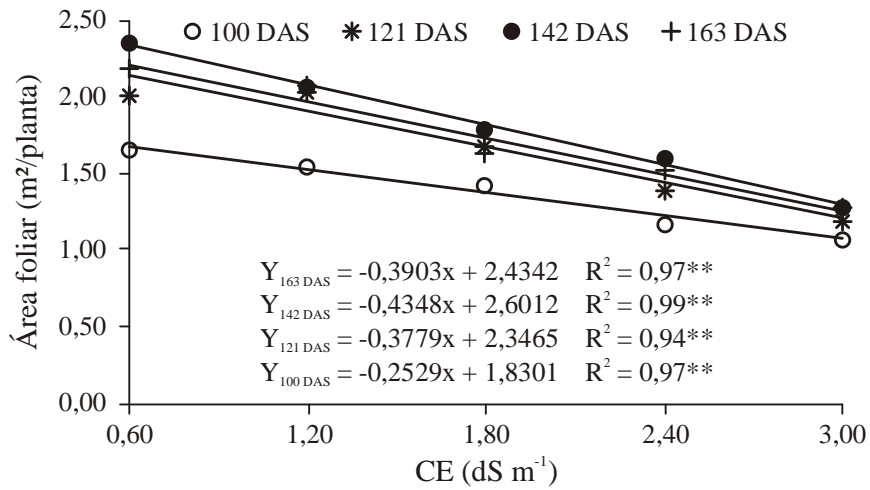

C.

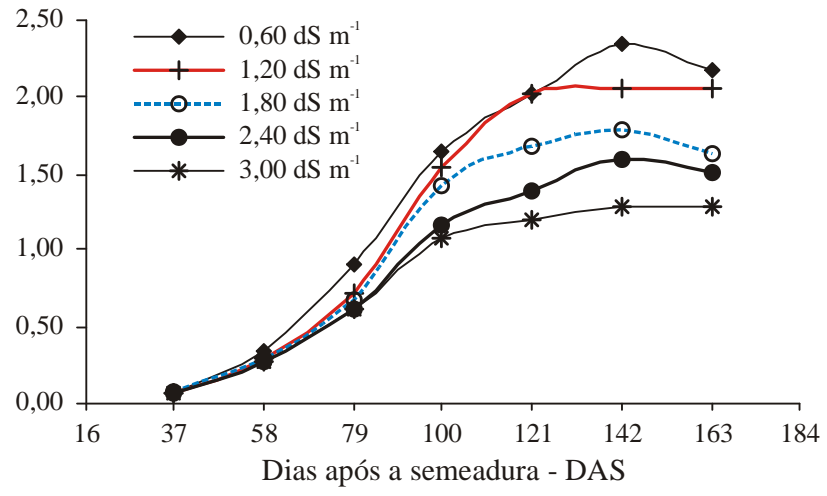

Figura 4. Área foliar de plantas de pinhão-manso aos 37, 58 e 79 dias após a semeadura - DAS (A) e aos 100,121, 142 e 163 DAS (B), em função da condutividade elétrica da água de irrigação (CEa) e sua evolução temporal (C), em função dos DAS

comprovadas reduções de 14,04 e $17,74 \%$ na $\mathrm{AF}$, respectivamente, para cada incremento unitário da condutividade elética $\left(\mathrm{dS} \mathrm{m}^{-1}\right)$; o decréscimo da área foliar está relacionado, provavelmente, a um dos mecanismos de adaptação da planta ao estresse salino, diminuindo a sua superfície transpirante (Tester \& Davenport, 2003).

A redução da AF decorre da diminuição do volume das células, segundo Lauchli \& Epstein (1990), Araújo (1994) e Souza (1995), aumentando, indiretamente, a concentração total de solutos na folha, contribuindo para o ajustamento osmótico e adaptação à salinidade.

Analisando-se a evolução da área foliar, ao longo do período de estudos (Figura 4C), nota-se que os efeitos da salinidade se foram intensificando, com o tempo, atingindo o máximo aos 142 dias, reduzindo-se ou estabilizando-se depois dessa data. Em média, a AF variou entre 0,0633 $\mathrm{m}^{2}$ aos 37 dias, e 1,8186 $\mathrm{m}^{2}$ aos 142 dias, reduzindo-se após essa data, até os 163 DAS, quando a área média observada foi de $1,7316 \mathrm{~m}^{2}$. Para Benincasa (2003), o declínio da área foliar à medida que as plantas se desenvolvem, também pode ser decorrente do auto-sombreamento, acarretando abscisão de folhas, o que não pode ser a explicação para o presente caso, considerando ter ocorrido aumento do número de folhas, em todos os tratamentos, como observado na Figura 3C.

\section{CONCLUSÕES}

1. Aos 163 dias após a semeadura, a altura de plantas, o diâmetro caulinar, o número de folhas e a área foliar do pinhão-manso são afetados linearmente, com decréscimos de $3,78,7,35,9,75$ e $17,74 \%$, respectivamente, por aumento unitário da $\mathrm{CEa}$, em ambiente protegido.

2. A área foliar, dentre as varáveis de crescimento, por ser a variável mais afetada é a que melhor expressa os efeitos da salinidade da água sobre o pinhão-manso.

\section{LITERATURA CITADA}

ABA - Anuário Brasileiro de Agroenergia. Pinhão manso. Santa Cruz do Sul: Gazeta, 2007. 520p.

Araújo, C. A. S. Avaliação de feijoeiros quanto à tolerância à salinidade em solução nutritiva. Viçosa: UFV, 1994. 87p. Dissertação Mestrado

Arruda, F. P. de. Emissão/abscisão de órgãos reprodutivos do algodoeiro herbáceo, cv. CNPA 7H, em função do sistema de manejo do solo e dos estresses hídricos e salino. Areia: UFPB, 92p. 1999. Dissertação Mestrado

Arruda, F. P. de; Beltrão, N. E. de M.; Andrade, A. P. de; Pereira, W. E.; Severino, L. S. Cultivo do pinhão manso (Jatropha curcas L.) como alternativa para o Semi-Árido Nordestino. Revista Brasileira de Oleaginosas e Fibrosas, v.8, n.1, p.789-799, 2004.

Ayers, R. S.; Westcot, D. W. A qualidade da água na agricultura. Campina Grande: UFPB, 1999. 218p. Estudos FAO. Irrigação e Drenagem, 29.

Beltrão, N. E. de M. Considerações gerais sobre o pinhão manso (Jatropha curcas L.) e a necessidade urgente de pesquisas, desenvolvimento e inovações tecnológicas para esta planta nas condições brasileiras. Campina Grande: EMBRAPA. 2006. 4p.

Benincasa, M. M. P. Análise de crescimento de plantas. Jaboticabal: FUNEP, 2003. 41p.

Bernardo, S.; Soares, A. A.; Mantovani, E. C. Manual de irrigação. 8.ed. Viçosa: UFV; Imprensa Universitária, 2006. 625p.

Cáceres, D. R.; Portas, A. A.; Abramides, J. E. Pinhão-manso. 2007. <http://www.infobibos.com/Artigos/2007_3/pinhaomanso>. 17 Fev. 2008.

Cavalcanti, M. L. F. Germinação e crescimento inicial da mamoneira irrigada com águas salinas. Campina Grande: UFCG, 2003. 46p. Dissertação Mestrado 
Cavalcanti, M. L. F.; Fernandes, P. D.; Gheyi, H. R.; Barros Júnior, G.; Soares, F. A. L.; Siqueira, E. C. Tolerância da mamoneira BRS 149 à salinidade: Germinação e características de crescimento. Revista Brasileira de Engenharia Agrícola e Ambiental, v.9, Suplemento, p.57-61, 2005a.

Cavalcanti, M. L. F.; Fernandes, P. D.; Gheyi, H. R.; Barros Júnior, G.; Soares, F. A. L.; Siqueira, E. C. Índices ecofisiológicos da mamoneira sob estresse salino. Revista Brasileira de Engenharia Agrícola e Ambiental, v.9, Suplemento, p.66-70, 2005b.

Correia, K. G. Índices fenológicos e fisiológicos de amendoim sob estresse salino. Campina Grande: UFCG, 2005. 67p. Dissertação Mestrado

Correia, K. G. Fernandes, P. D.; Gheyi, H. R.; Gurgel, M. T.; Rodrigues, L. N. Crescimento do amendoinzeiro irrigado com águas salinas. Revista Brasileira de Engenharia Agrícola e Ambiental, v.9, Suplemento, p.81-85, 2005.

Fageria, N. K. Solos tropicais e aspectos fisiológicos das culturas. Brasília: EMBRAPA/DPU, 1989. 425p. Documento, 18

Jácome, A. G.; Fernandes, P. D.; Gheyi, H. R.; Gonçalves, A. C. A.; Silva, F. F. Avaliação de genótipos de algodoeiro sob níveis de salinidade da água de irrigação. Revista Brasileira de Engenharia Agrícola e Ambiental, v.9, Suplemento, p.365-369, 2005.

Lauchli, A.; Epstein, E. Plant responses to saline and sodic conditions. In: Tanji, K. K. (ed.) Agricultural salinity assessment and management. New York: SCE, 1990. p.113-137.

Maas, E. V.; Nieman, R. H. Physiology of plant tolerance to salinity. In: Jung, G. A. (ed.) Crop tolerance to suboptimal land conditions. Madison: ASA, 1978. p.227-299.

Medeiros, J. F de. Qualidade de água de irrigação e evolução da salinidade nas propriedades assistidas pelo GAT nos Estados de RN, PB e CE. Campina Grande: UFPB, 1992. 173p. Dissertação Mestrado

Novais, R. F.; Neves, J. C. L.; Barros, N. F. Ensaio em ambiente controlado. In: Oliveira, A. J. de; Garrido, W. E.; Araújo, J. D. de; Lourenço, S. (coord.). Métodos de pesquisa em fertilidade do solo. Brasília: EMBRAPA. 1991. cap.2, p.189-198. Documento, 3
Pizarro, F. Drenaje agricola y recuperacion de suelos salinos. 2.ed. Madri: Editorial Española S.A., 1985. 542p.

Queiroz, S. O. P. de; Büll, L. T. Comportamento de genótipos de algodão herbáceo em função da salinidade do solo. Irriga, v.6, n.2, p.124-134, 2001.

Rhoades, J. D.; Kandiah, A.; Mashali, A. M. Uso de águas salinas para produção agrícola. Campina Grande: UFPB, 2000, 117p. Estudos da FAO, Irrigação e Drenagem, 48, revisado

Santos, J. W. dos; Moreira, J. de A. N.; Beltrão, N. E. de M. Avaliação do emprego dos testes de comparação de médias na revista Pesquisa Agropecuária Brasileira (PAB) de 1980 a 1994. Pesquisa Agropecuária Brasileira, v.33, n.3, p.225-230, 1998.

Shannon, M. C. Quest of rapid screening techniques for plant salt tolerance. Horticulture Science, v.14, p.587-589, 1979.

Silva, S. M. S. Germinação, crescimento e desenvolvimento de genótipos de mamoneiro irrigados com águas salinas. Campina Grande: UFCG, 2004. 74p. Dissertação Mestrado

Silva, S. M. S.; Alves, A. N.; Gheyi, H. R.; Beltrão, N. E. de M.; Severino, L. S.; Soares, F. A. L. Germinação e crescimento inicial de duas cultivares de mamoneira sob estresse salino. Revista Brasileira de Engenharia Agrícola e Ambiental, v.9, Suplemento, p.347-352, 2005.

Souza, M. R. Comportamento do feijoeiro (Phaseolus vulgaris L. cv Eriparza) submetido a diferentes níveis de salinidade da água de irrigação. Campina Grande: UFPB, 1995. 94p. Dissertação Mestrado

Taiz, L.; Zeiger, E. Fisiologia vegetal. 2.ed. Porto Alegre: Artmed, 2004. 719p.

Tester, M.; Davenport, R. $\mathrm{Na}^{+}$tolerance and $\mathrm{Na}^{+}$transport in higher plants. Annals of Botany, v.91, p.503-527, 2003.

Tominaga, N.; Kakida, J.; Yasuda, E. K.; Sousa, L. A. S.; Resende, P. L.; Silva, N. da D. Cultivo do pinhão-manso para produção de biodiesel. Viçosa: Centro de Produções Técnicas, 2007. 220p.

Vale, L. S.; Severino, L. S.; Beltrão, N. E. de M. Efeito da salinidade da água sobre o pinhão manso. In: Congresso da Rede Brasileira de Tecnologia do Biodiesel. 1, 2006, Brasília. Anais... Brasília: IBPS. Anais... 2006. p.87-90. 